SciDioc

\section{A Comparative Analysis into Occlusal Morphology Developed From Cad Created Anatomy to Hand Layered Anatomy}

Research Article

J.S Thaslima Nandhini ${ }^{1}$, Suresh venugopalan ${ }^{2 *}$, M. Jeevitha ${ }^{3}$

${ }^{1}$ Saveetha Dental College and Hospitals, Saveetha Institute of Medical and Technical Sciences(SIMATS), Saveetha University, Chennai 600077 , Tamil Nadu, India.

${ }^{2}$ Reader, Department of Prosthodontics, Saveetha Dental College and Hospitals, Saveetha Institute of Medical and Technical Sciences(SIMATS), Saveetha University, Chennai 600 077, Tamil Nadu, India.

${ }^{3}$ Senior Lecturer, Department of periodontics, Saveetha Dental College and Hospitals, Saveetha Institute of Medical and Technical Sciences(SIMATS), Saveetha University, Chennai 600 077, Tamil Nadu, India.

\title{
Abstract
}

The aim of the study is to assess the occlusal contacts between the two different types of prosthetics and comparison of occlusal morphology of CAD created and hand layered anatomy crown. A total of 960 case sheets were reviewed. Out of this 200 patients were selected randomly who had fixed dental prosthesis treatment. The study was done in saveetha dental college and hospitals. We reviewed patients records and analysed the data of 86000 patients between June 2019 and March 2020. Approval of the ethical committee was taken before the start of the study. Excel tabulation is done. Data was analysed by SPSS statistics software. Chisquare statistics test is done. P valve was set as 0.05 as a level of significance. Then management and outcome were analysed. Data search of fixed prosthesis led to 960 patients of which 200 patients were randomly selected based on inclusion criteria. Occlusal morphology is assessed for CAD created anatomy to hand layered anatomy of the crown. Incidence of monolithic crown in the posterior region $(30 \%)$ and hand layered zirconia $(35 \%)$ is most commonly seen in the anterior region. Monolithic crown $(55.8 \%)$ is a most commonly used type of crown in fixed dental prosthesis. Our study shows, monolithic crown is most commonly used in the posterior region and hand layered zirconia is used in anterior surface. Cuspal anatomy/incsal anatomy as well as over contoured/ encountered anatomy is well defined in monolithic crown.

Keywords: Fixed Dental Prosthesis; CAD/CAM; Dental Margin Adaptation; Occlusal Anatomy.

\section{Introduction}

Application of computer aided design and computer aided manufacturing (CAD/CAM) technology in the late 1980s, the restorative dentistry has been changing the manual fabrication of tooth restoration towards a more computerized fabrication $[1,2]$. CAD/ CAM prosthetic treatment with high performance became an alternative to traditional technologies due to quickness of chairside fabrication of the final restoration $[3,4]$. Use of CAD/CAM technology has been increasing, as verified in previous studies. Despite the fact that CAD/CAM technology has significantly improved over time and has been shown to be approximately $16 \%$, More time efficient in ceramic prosthesis fabrication than the convention method and CAD/CAM resulted in better in terms of internal fit compared to conventional crowns [5-7]. The CAD/ CAM technology can be divided into three systems according to their production methods $[8,9]$. The chairside system is a viable alternative to traditional procedures with several advantages- it eliminates the need for temporary restorations, increases the durability of dental tissue adhesion and reduces the durability of the dental tissue adhesion and reduces a postoperative sensitivity thus improving the efficiency [10-12]. With the development of $\mathrm{CAD} / \mathrm{CAM}$ systems and rapid improvements in the mechanical properties of ceramic materials, zirconia has become more popular. The zirconia is veneered with porcelain when used clinically to overcome poor optical properties [13].

Monolithic zirconia restorations were used to avoid the chipping

*Corresponding Author:

Suresh Venugopalan,

Reader, Department of prosthodontics, Saveetha Dental College and Hospitals, Saveetha Institute of Medical and Technical Sciences (SIMATS), Saveetha University, 162, PH Road, Chennai 600077, TamilNadu, India.

Tel: :+919543192858

E-mail: suresh@saveetha.com

Received: September 03, 2019

Accepted: September 29, 2019

Published: September 30, 2019

Citation: J.S Thaslima Nandhini, Suresh venugopalan, M. Jeevitha. A Comparative Analysis into Occlusal Morphology Developed From Cad Created Anatomy to Hand Layered Anatomy. Int J Dentistry Oral Sci. 2019;S2:02:009:33-37. doi: http://dx.doi.org/10.19070/2377-8075-SI02-02009

Copyright: Suresh Venugopalan 2019 . This is an open-access article distributed under the terms of the Creative Commons Attribution License, which permits unrestricted use, distribution and reproduction in any medium, provided the original author and source are credited. 
of the veneering $[14,15]$. The poor optical properties of traditional restorations have been overcome by the development of translucent zirconia [16]. Fabrication of zirconia monolithic restorations improve the mechanical stability and also increase the range of indications of those prostheses [17]. but its wear behavior and chemical stability have not yet been fully clarified [18-20]. The CAD/CAM limits creation of anatomic details, may result in a deviant shape of the crowns [21]. Most of the crowns result in excellent anatomy [22]. CAD/CAM crown design is a completely different procedure than the handmade wax-up technique and may have an effect on the anatomical design of the crowns [23]. The margins are all satisfactory, and the other features like anatomy and contourness features were just distinguishable during probing $[24,25]$. The preparation margins are all shallow chamfer shaped and should be easily detected on a plaster model [26]. The laboratory technique unlikely causes some short crown margins. Difference in ceramic material manufacturing technique brings into question which method presents higher survival rates [27].

The estimated five year survival of all ceramic crown ranges $90.7 \%$ whereas the clinical performances of CAD/CAM single tooth restorations has been reported to be estimated tooth survival of $91.6 \%$ after five years [28] chipping and fractures of veneering ceramic is thus a problem both on metal and all ceramic crowns [29]. In recent years high strength monolithic zirconia shows a superficial glazing and staining which tested with a high load earring area [30]. The aim of the present study is to compare the occlusal morphology of CAD created and hand layered crown and Anatomic and contouring will be evaluated occlusally.

\section{Materials and Methods}

The study was done in saveetha dental college and hospitals Chennai, India. We reviewed patients records and analysed the data of 86000 patients between June 2019 and March 2020. In that records were studied, who had a treatment of fixed dental prosthesis. There were both male patients as well as female patients. Approval of the ethical committee was taken before the start of the study. Evaluation of data was based on photographs. In photographs occlusal morphology and contour of the crown is analysed and depending upon the occlusal morphology score is given. Total sample was randomly selected by inclusion of all available data and out of 960 patients 200 patients were random- ly chosen with all required information. Information regarding occlusal morphology of CAD created as well as hand layered crown were analysed. Both internal and external validity is available. Tabulation is done on excel sheets. Data were analysed using SPSS statistical software. Descriptive statistics and bi-varient data analysis using chi-square test was done, confidence level was set at $95 \%$.

\section{Results and Discussion}

Out of 960 cases sheets reviewed, randomly 200 cases were assessed based on data availability. Occlusal morphology is assessed for CAD created anatomy to hand layered anatomy of the crown. The proportion of male with fixed dental prosthesis $(52.3 \%)$ is greater than female $(47.7 \%)$. Age above 40 years $(70 \%)$ had a high treatment of fixed dental prosthesis. Incidence of monolithic crown in the posterior region (30\%) is higher than the anterior region $(25.5 \%)$. Monolithic crown is a most commonly used type of crown in fixed dental prosthesis $(55.8 \%)$. Cuspal anatomy of the monolithic crown (39.7\%) is more acceptable than the hand layered crown (27.6\%). Contourness of monolithic crown $(37.6 \%)$ is well defined than the hand layered zirconia crown $(26 \%)$.

There is difference among occlusal morphology(cuspal anatomy/ incisal anatomy and over contoured / uncontoured) in monolithic crown and hand layered crown. Chi-square test shows statistically not significant $\mathrm{P}>0.05$. Although while comparing anterior to posterior- monolithic were preferred for posteriors and for anteriors hand layered were preferred. Comparison of type of crown and site of crown shows monolithic crown is most commonly used in the posterior region $(30 \%)$ whereas hand layered zirconia crown is commonly seen in anterior region(35\%) [Figure 1]. Analysis of the type of crown shows a monolithic crown $(55.8 \%)$ is more commonly used than the hand layered zirconia crown $(44.2 \%)$. [Figure 2]. Comparison of monolithic crown/ hand layered zirconia crown and occlusal morphology(cuspal anatomy/incisal anatomy) monolithic crown $(39.7 \%)$ has an acceptable anatomy than the hand layered zirconia crown $(27.6 \%)$ [Figure 3]. Comparison of monolithic/hand layered zirconia crown and occlusal morphology(over contoured/under contoured) monolithic crown $(37.6 \%)$ has a well defined contourness when compared with hand layered zirconia crown(26\%) [Figure 4]. Our study shows, monolithic crown is most commonly used in the posterior

Figure 1. Bar graph shows association of site of crowns and type of crown. $X$ axis represents the site of the crown and $Y$ axis represents the number of patients with fixed dental prosthesis. From the graph it is evident that the monolithic crown (red colour) is more commonly seen in the posterior region and hand layered zirconia (blue color) in the anterior region. Chi-square test $\mathrm{p}-0.000$ ( $\mathrm{p}<0.05$ indicating statistically significant).

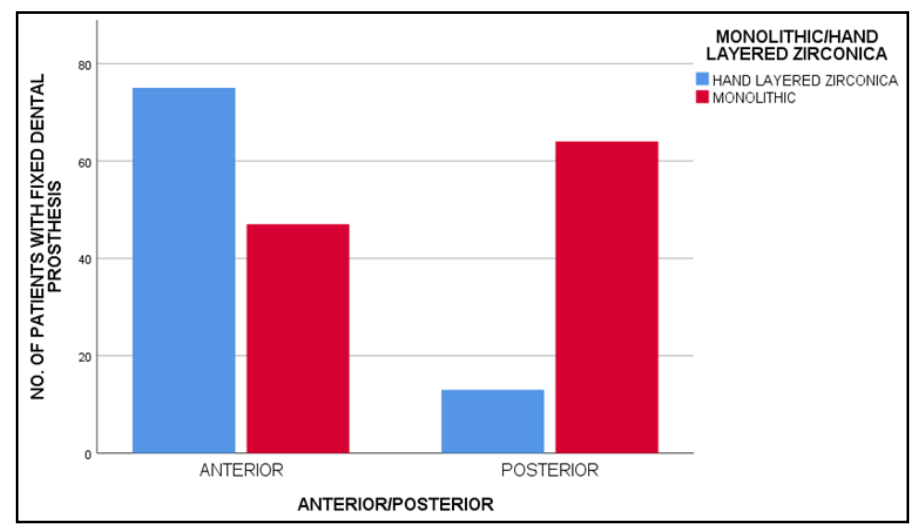


Figure 2. Bar graph showing frequency distribution of type of crown. $\mathrm{X}$ axis represents type of crown and $\mathrm{Y}$ axis represents number of patients with fixed dental prosthesis. Monolithic crown (red colour) more commonly used than the hand layered zirconia crown (blue colour). Hence Monolithic crown is more preferred than the hand layered zirconia crown for the treatment of fixed dental prosthesis.

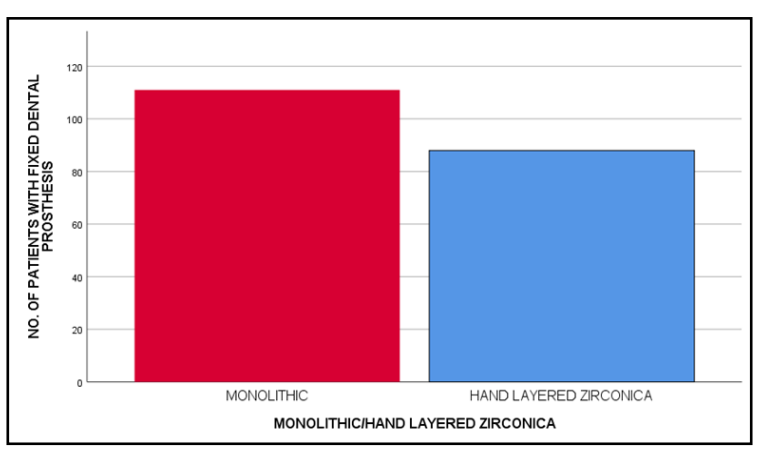

Figure 3. Bar chart showing association of monolithic crown/ hand layered zirconia crown and occlusal morphology (cuspal anatomy/incisal anatomy). $\mathrm{X}$ axis represents occlusal morphology (acceptable anatomy/unacceptable anatomy). $Y$ axis represents the number of patients with fixed dental prosthesis. Monolithic crown (red colour) has a higher number of acceptable anatomy than the hand layered zirconia crown (blue). From this graph it is evident that the monolithic crown has an acceptable anatomy than the hand layered zirconia crown. Chi-square test $\mathrm{p}-0.195$ ( $\mathrm{p}>0.05$ indicating statistically not significant).

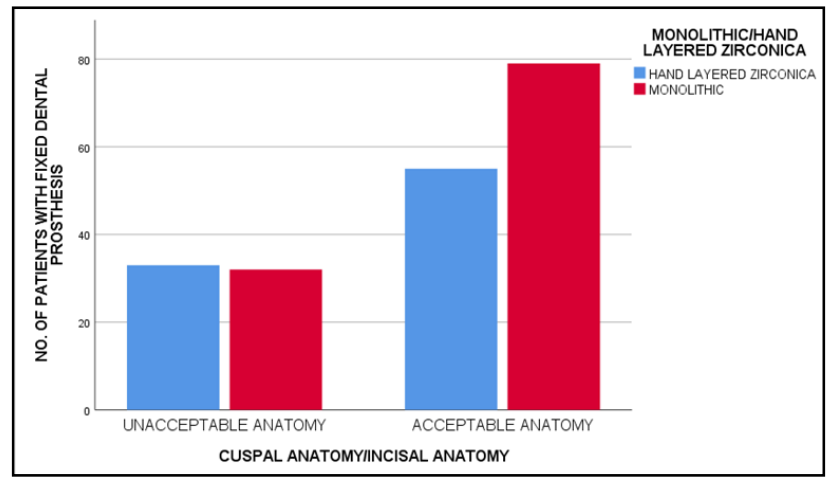

Figure 4. Bar chart showing association of monolithic/hand layered zirconia crown and occlusal morphology (over contoured/under contoured). $\mathrm{Y}$ axis represents the number of patients with fixed dental prosthesis. $\mathrm{X}$ axis represents occlusal morphology (unacceptable contour/ acceptable contour). Monolithic crown (red colour) has a higher number of acceptable contour than the hand layered zirconia crown (blue). From this graph it is evident that the monolithic crown has a well defined contourness when compared to hand layered zirconia crown. Chi-square test p- 0.216 ( $p>0.05$ indicating statistically not significant).

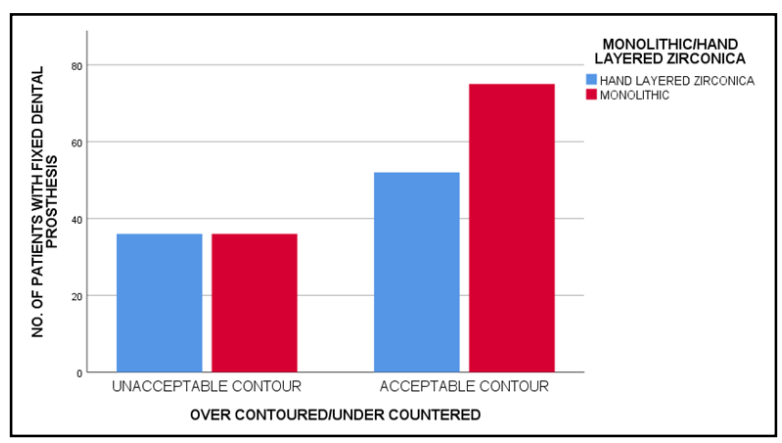

region and hand layered zirconia is used in anterior surface. Cuspal anatomy/incsal anatomy as well as over contoured/encountered anatomy is well defined in monolithic crown.

The natural and harmonious morphology is of great significance to a crown $[31,32]$. Reconstructing functional occlusal and axial surfaces in coordination with adjacent teeth and opposite teeth is very important for the stability [33]. Accurately reconstructing morphology can reduce the adjustment time, theory reducing the chairside operation time. The design of the crown using the chairside system is mainly completed by technicians independently, sometimes technicians lack design knowledge about crown morphology and results in various complications in fabrication of prosthesis.

The results of this study shows cuspal anatomy of a monolithic crown $(79 \%)$ is more acceptable than the hand layered zirconia crown (55\%). These results coincide with study provided by Kollmuss $\mathrm{M}$ et al., in 2016, he stated that laboratory crowns show significantly more occlusal contacts than the conventional crowns. 
LABCAD crown has a least time of occlusal adaptation and good esthetic gradings [31]. But this study contradicts with Reich S et al in 2010, he stated that CAD/CAM least occlusal morphology than the conventional crowns [34]. Monolithic crown(75\%) has a well defined acceptable contour than the hand layered zirconia $(52 \%)$, this study differs with a study provided by a Christian schwier et al in 2018, he stated monolithic crown has a too short margins-over contours(47.7\%) [35]. Nil roar gred et al in 2017, stated over contoured seen in monolithic zirconia crown and reduced marginal fit. There is a difference among occlusal morphology in monolithic crown and hand layered zirconia crown which is statistically significant $\mathrm{P}<0.05$ [36]. Although, while comparing anterior to posterior, monolithic were preferred for posterior and for anterior hand layered were preferred. From the overall results acceptance of CAD/CAM restorations is a choice of restoration currently used, The monolithic crown is more commonly used than the hand layered in posterior restorations. The monolithic crown has a well acceptable anatomy and defined contouring than the hand layered zirconia crown. The present study evaluated data with relevant photographs; those with unclear data were not considered in reporting. Future scope of the present study can be a multicentric study with more analyzing parameters.

\section{Acknowledgement and Declaration}

We authors thank Saveetha Dental College and the information department associated with the institution for providing us enormous data and permission to access to conduct the original study.

\section{Conclusion}

The present study indicates the overall acceptance of CAD/CAM restorations as a choice of restoration currently are excellent by reviewing its sheer volume of use. The monolithic is preferred over hand layered in posterior restorations for its acceptable anatomy and function. The Hand layered were preferred in the anterior restoration and both types of studied restoration's anatomy and contouring were good but required more precision detailing.

\section{References}

[1]. Zhang R, Ding Q, Sun Y, Zhang L, Xie Q. Assessment of CAD-CAM zirconia crowns designed with 2 different methods: A self-controlled clinical trial. J Prosthet Dent. 2018 Nov;120(5):686-692.Pubmed PMID: 29807740.

[2]. Mehl A, Blanz V, Hickel R. Biogeneric tooth: a new mathematical representation for tooth morphology in lower first molars. Eur J Oral Sci. 2005 Aug;113(4):333-40.Pubmed PMID: 16048526.

[3]. Chochlidakis KM, Papaspyridakos P, Geminiani A, Chen CJ, Feng IJ, Ercoli C. Digital versus conventional impressions for fixed prosthodontics: A systematic review and meta-analysis. J Prosthet Dent. 2016 Aug 1;116(2):18490.

[4]. Bindl L, Dresbach K, Lentze MJ. Incidence of acute respiratory distress syndrome in German children and adolescents: a population-based study. Crit Care Med. 2005 Jan;33(1):209-312.Pubmed PMID: 15644671.

[5]. Joda T, Brägger U. Digital vs. conventional implant prosthetic workflows: a cost/time analysis. Clin Oral Implants Res. 2015 Dec;26(12):1430-5.Pubmed PMID: 25179680.

[6]. Kassardjian V, Varma S, Andiappan M, Creugers NHJ, Bartlett D. A systematic review and meta analysis of the longevity of anterior and posterior all-ceramic crowns. J Dent. 2016 Dec;55:1-6.Pubmed PMID: 27594093.

[7]. Kumar GA, Kovoor LC, Oommen VM. Three-dimensional finite element analysis of the stress distribution around the implant and tooth in tooth implant-supported fixed prosthesis designs. J Dent Implant. 2011 Jul 1;1(2):75.

[8]. Woo TC, Janardan R. Computational geometry and computer-aided design and manufacturing. CAD. 1998;30(4):229.

[9]. Mörmann WH, Bindl A. All-ceramic, chair-side computer-aided design/ computer-aided machining restorations. Dent Clin North Am. 2002 Apr;46(2):405-26.Pubmed PMID: 12014040

[10]. Ashok V, Nallaswamy D, Benazir Begum S, Nesappan T. Lip Bumper Prosthesis for an Acromegaly Patient: A Clinical Report. J Indian Prosthodont Soc. 2014 Dec;14(Suppl 1):279-82.Pubmed PMID: 26199531.

[11]. Subasree S, Murthykumar K. Effect of Aloe Vera in Oral Health-A Review. Res J Pharm Technol. 2016;9(5):609-12.

[12]. Jyothi S, Robin PK, Ganapathy D. Periodontal health status of three different groups wearing temporary partial denture. Res J Pharm Technol. 2017;10(12):4339-42.

[13]. Zhang Y. Making yttria-stabilized tetragonal zirconia translucent. Dent Mater. 2014 Oct;30(10):1195-203.Pubmed PMID: 25193781.

[14]. Grohmann P, Bindl A, Hämmerle C, Mehl A, Sailer I. Three-unit posterior zirconia-ceramic fixed dental prostheses (FDPs) veneered with layered and milled (CAD-on) veneering ceramics: 1-year follow-up of a randomized controlled clinical trial. Quintessence Int. 2015 Nov-Dec;46(10):871-80. Pubmed PMID: 26345100.

[15]. Ranganathan H, Ganapathy DM, Jain AR. Cervical and Incisal Marginal Discrepancy in Ceramic Laminate Veneering Materials: A SEM Analysis. Contemp Clin Dent. 2017 Apr-Jun;8(2):272-278.Pubmed PMID: 28839415.

[16]. Lan TH, Pan CY, Liu PH, Chou MMC. Fracture Resistance of Monolithic Zirconia Crowns in Implant Prostheses in Patients with Bruxism. Materials (Basel). 2019 May 17;12(10):1623.Pubmed PMID: 31108872.

[17]. Vijayalakshmi B, Ganapathy D. Medical management of cellulitis. Res J Pharm Technol. 2016;9(11):2067-70.

[18]. Flinn BD, deGroot DA, Mancl LA, Raigrodski AJ. Accelerated aging characteristics of three yttria-stabilized tetragonal zirconia polycrystalline dental materials. J Prosthet Dent. 2012 Oct;108(4):223-30.Pubmed PMID: 23031728.

[19]. Venugopalan S, Ariga P, Aggarwal P, Viswanath A. Magnetically retained silicone facial prosthesis. Niger. J. Clin. Pract. 2014 Mar 27;17(2):260-4.

[20]. Kannan A, Venugopalan S. A systematic review on the effect of use of impregnated retraction cords on gingiva. Res J Pharm Technol. 2018;11(5):2121-6.

[21]. Duraisamy R, Krishnan CS, Ramasubramanian H, Sampathkumar J, Mariappan S, Navarasampatti Sivaprakasam A. Compatibility of Nonoriginal Abutments With Implants: Evaluation of Microgap at the Implant-Abutment Interface, With Original and Nonoriginal Abutments. Implant Dent. 2019 Jun;28(3):289-295.Pubmed PMID: 31124826.

[22]. Basha FYS, Ganapathy D, Venugopalan S. Oral Hygiene Status among Pregnant Women.Res J Pharm Technol. 2018;11:3099.

[23]. Kannan A. Effect of Coated Surfaces influencing Screw Loosening in Implants: A Systematic Review and Meta-analysis. World J. Dent. 2017 Nov;8(6):496-502.

[24]. Cehreli MC, Kökat AM, Akça K. CAD/CAM Zirconia vs. slip-cast glassinfiltrated Alumina/Zirconia all-ceramic crowns: 2-year results of a randomized controlled clinical trial. J Appl Oral Sci. 2009 Jan-Feb;17(1):49-55. Pubmed PMID: 19148406.

[25]. Selvan SR, Ganapathy D. Efficacy of fifth generation cephalosporins against methicillin-resistant Staphylococcus aureus-A review. Res J Pharm Technol. 2016;9(10):1815-8.

[26]. Jain AR, Nallaswamy D, Ariga P, Ganapathy DM. Determination of correlation of width of maxillary anterior teeth using extraoral and intraoral factors in Indian population: A systematic review. World J Dent. 2018 Jan;9:68-75.

[27]. Ajay R, Suma K, Ali SA, Kumar Sivakumar JS, Rakshagan V, Devaki V, et al. Effect of Surface Modifications on the Retention of Cement-retained Implant Crowns under Fatigue Loads: An In vitro Study. J Pharm Bioallied Sci. 2017 Nov;9(Suppl 1):S154-S160.Pubmed PMID: 29284956.

[28]. Alves de Carvalho IF, Santos Marques TM, Araújo FM, Azevedo LF, Donato H, Correia A. Clinical Performance of CAD/CAM Tooth-Supported Ceramic Restorations: A Systematic Review. Int J Periodontics Restorative Dent. 2018 Jul/Aug;38(4):e68-e78.Pubmed PMID: 29889916.

[29]. Ganapathy D, Sathyamoorthy A, Ranganathan H, Murthykumar K. Effect of Resin Bonded Luting Agents Influencing Marginal Discrepancy in All Ceramic Complete Veneer Crowns. J Clin Diagn Res. 2016 Dec;10(12):ZC67ZC70.Pubmed PMID: 28209008.

[30]. Sailer I, Makarov NA, Thoma DS, Zwahlen M, Pjetursson BE. Corrigendum to "All-ceramic or metal-ceramic tooth- supported fixed dental prostheses (FDPs)? A systematic review of the survival and complication rates. Part I: Single crowns (SCs)" [Dental Materials 31 (6) (2015) 603-623]. Dent Mater. 2016 Dec;32(12):e389-e390.Pubmed PMID: 27726969.

[31]. Kollmuss M, Kist S, Goeke JE, Hickel R, Huth KC. Comparison of chairside and laboratory CAD/CAM to conventional produced all-ceramic crowns regarding morphology, occlusion, and aesthetics. Clin Oral Investig. 2016 May;20(4):791-7.Pubmed PMID: 26245275.

[32]. Arslan Y, Karakoca Nemli S, Bankoğlu Güngör M, Tamam E, Yılmaz H. Evaluation of biogeneric design techniques with CEREC CAD/CAM sys- 
tem. J Adv Prosthodont. 2015 Dec;7(6):431-6.Pubmed PMID: 26816572.

[33]. Eftekhar Ashtiani R, Nasiri Khanlar L, Mahshid M, Moshaverinia A. Comparison of dimensional accuracy of conventionally and digitally manufactured intracoronal restorations. J Prosthet Dent. 2018 Feb;119(2):233-238. Pubmed PMID: 28578984.

[34]. Reich S, Trentzsch L, Gozdowski S, Krey KF. In vitro analysis of laboratoryprocessed and CAD/CAM-generated occlusal onlay surfaces. Int J Prosthodont. 2009 Nov-Dec;22(6):620-2.Pubmed PMID: 19918600.
[35]. Schriwer C, Skjold A, Gjerdet NR, Øilo M. Monolithic zirconia dental crowns. Internal fit, margin quality, fracture mode and load at fracture. Dent Mater. 2017 Sep;33(9):1012-1020.Pubmed PMID: 28662859.

[36]. Hansen TL, Schriwer C, Øilo M, Gjengedal H. Monolithic zirconia crowns in the aesthetic zone in heavy grinders with severe tooth wear - An observational case-series. J Dent. 2018 May;72:14-20.Pubmed PMID: 29452242. 